\title{
Metabolic Syndrome, Components, and Cardiovascular Disease Prevalence in Chronic Kidney Disease: Findings from the Chronic Renal Insufficiency Cohort (CRIC) Study
}

\author{
Raymond R. Townsend ${ }^{a} \quad$ Amanda H. Anderson $^{b}$ Jing Chen ${ }^{c}$ \\ Crystal A. Gadebegku ${ }^{d}$ Harold I. Feldman ${ }^{a}$ b Jeffrey C. Fink ${ }^{e}$ Alan S. Go ${ }^{f}$ \\ Marshall Joffe $^{a, b}$ Lisa A. Nessel ${ }^{b}$ Akinlolu Ojo ${ }^{d}$ Daniel J. Rader ${ }^{a}$ \\ Muredach P. Reilly ${ }^{\mathrm{a}}$ Valerie Teal ${ }^{\mathrm{b}}$ Karen Teffa, ${ }^{\mathrm{b}} \quad$ Jackson T. Wright ${ }^{\mathrm{g}}$ \\ Dawei Xie ${ }^{b}$ for the CRIC Study Investigators

\begin{abstract}
${ }^{a}$ Department of Medicine and ${ }^{b}$ Center for Clinical Epidemiology and Biostatistics, Department of Biostatistics and Epidemiology, University of Pennsylvania Medical Center, Philadelphia, Pa., 'Department of Medicine, Tulane University School of Medicine, New Orleans, La., ${ }^{\mathrm{d}}$ Department of Internal Medicine, University of Michigan Health System, Ann Arbor, Mich., ${ }^{~}$ Department of Medicine, University of Maryland, Baltimore, Md., f Kaiser Permanente Northern California, University of California, Oakland, Calif., and ${ }^{9}$ Department of Medicine, Case Western Reserve University, Cleveland, Ohio, USA
\end{abstract}

\section{Key Words}

Cardiovascular disease $\cdot$ Chronic kidney disease $\cdot$ Chronic Renal Insufficiency Cohort (CRIC) Study · Metabolic syndrome

\footnotetext{
Abstract

Background/Aims: Metabolic syndrome may increase the risk for incident cardiovascular disease (CVD) and all-cause mortality in the general population. It is unclear whether, and to what degree, metabolic syndrome is associated with CVD in chronic kidney disease (CKD). We determined metabolic syndrome prevalence among individuals with a broad spectrum of kidney dysfunction, examining the role of the individual elements of metabolic syndrome and their relationship to prevalent CVD. Methods: We evaluated four models to compare metabolic syndrome or its compo-
}

nents to predict prevalent CVD using prevalence ratios in the Chronic Renal Insufficiency Cohort (CRIC) Study. Results: Among 3,939 CKD participants, the prevalence of metabolic syndrome was $65 \%$ and there was a significant association with prevalent CVD. Metabolic syndrome was more common in diabetics $(87.5 \%)$ compared with non-diabetics (44.3\%). Hypertension was the most prevalent component, and increased triglycerides the least prevalent. Using the bayesian information criterion, we found that the factors defining metabolic syndrome, considered as a single intervalscaled variable, was the best of four models of metabolic syndrome, both for CKD participants overall and for diabetics and non-diabetics separately. Conclusion: The predictive value of this model for future CVD outcomes will subsequently be validated in longitudinal analyses.

Copyright $\odot 2011$ S. Karger AG, Basel

Raymond R. Townsend, MD

University of Pennsylvania, 122 Founders Building

3400 Spruce Street, Philadelphia, PA 19104 (USA)

Tel. +1 2156624630

E-Mail townsend@mail.med.upenn.edu 


\section{Introduction}

Prospective cohort studies report a higher incidence of cardiovascular disease (CVD) or mortality among patients with chronic kidney disease (CKD) [1-3]. For example, Go et al. [1] reported a progressive increase in the hazard ratios for CVD events using the estimated glomerular filtration rate (eGFR) beginning with values of $45-59$, and ending with values of $<15 \mathrm{ml} / \mathrm{min} / 1.73 \mathrm{~m}^{2}$ in a large, community-based population. Similarly, in the Cardiovascular Health Study the presence of CKD doubled the CVD mortality risk in a cohort of 5,808 older subjects [2] and demonstrated that even early decrements in kidney function, where eGFR was $>60 \mathrm{ml} / \mathrm{min} /$ $1.73 \mathrm{~m}^{2}$, assessed by cystatin C, were predictive of CVD [4]. Although it is not clear what contributes to such increased cardiovascular risk in patients with CKD, identifying the underlying risk factors associated with CVD among CKD patients could help to develop effective approaches for early screening and intervention in order to reduce the adverse CVD outcomes.

Metabolic syndrome, characterized by abdominal obesity, hypertriglyceridemia, low levels of high-density lipoprotein (HDL) cholesterol, elevated blood pressure (BP), and elevations in fasting glucose or diabetes, has been associated with an increased risk for the development of CVD as well as increased mortality from both CVD and all causes in the general population $[5,6]$. Recent meta-analyses found that the metabolic syndrome increases the risk for incident CVD (relative risks (RRs) ranging from 1.53 to 2.18 ) and all-cause mortality (RR $1.27-1.60)$ in the general population [7-9]. Metabolic syndrome is common in patients with CKD and an important risk factor for development and progression of CKD $[10,11]$. However, it is unclear whether metabolic syndrome predicts CVD in CKD. In this study, we examined the metabolic syndrome among individuals with a broad spectrum of kidney dysfunction, evaluating the syndrome itself compared with its individual elements and their relationship to prevalent CVD among participants of the Chronic Renal Insufficiency Cohort (CRIC) Study [12].

\section{Methods}

\section{Study Population}

The CRIC Study population includes a racially and ethnically diverse group of men and women aged $21-74$ years with mildto-moderate renal disease, $46 \%$ of whom have diabetes mellitus. CRIC participants were recruited between May 2003 and August
2008 from seven centers in the United States [12]. Patients were identified through laboratory database searches of recently measured serum creatinine values, referrals from physicians' offices, and self-referral. Patients with cirrhosis, HIV infection, polycystic kidney disease, renal cell carcinoma, a kidney transplant or on dialysis, or taking immunosuppressant drugs were excluded. Age-specific eGFR levels were used to define inclusion into the CRIC cohort: eGFR of $20-70 \mathrm{ml} / \mathrm{min} / 1.73 \mathrm{~m}^{2}$ for patients aged $21-44$ years, $20-60 \mathrm{ml} / \mathrm{min} / 1.73 \mathrm{~m}^{2}$ for ages $45-64$ years, and $20-$ $50 \mathrm{ml} / \mathrm{min} / 1.73 \mathrm{~m}^{2}$ for ages $65-74$ years. The current analysis is based on the experience of the 3,939 CRIC participants who completed the baseline study visit.

\section{Data Collection}

During the baseline study visit, all CRIC study data were collected by trained study staff using procedures and equipment that were standardized across study sites. A baseline medical history questionnaire was administered in which participants were queried about prior history of CVD. Responses to these questions were used to identify prevalent CVD. Participants were asked: 'Have you ever been diagnosed with, or has a doctor or other health professional ever told you that, you have "coronary artery disease (heart attack, angina), prior revascularization of your heart blood vessels (e.g. balloon angioplasty, coronary stenting, coronary bypass surgery)"'? For these analyses, coronary artery disease was defined as an affirmative response to questions about either coronary artery disease or prior coronary revascularization. Separate questions queried about a history of heart failure, stroke or transient ischemic attack, or peripheral vascular disease (including claudication, amputation or angioplasty). Questionnaires also assessed demographic characteristics. Body weight and height were each measured twice and averaged for analysis. Body mass index (BMI) was calculated as weight in kilograms divided by height in meters squared. Waist circumference was measured at the uppermost lateral border of the ilium with a Gulick II tape measure and repeated until two measures agreed within $1 \mathrm{~cm}$. Three BP measurements were obtained in the sitting position after at least 5 min of quiet rest by trained and certified staff according to a standard protocol using an aneroid sphygmomanometer and averaged to calculate systolic BP (SBP) and diastolic $\mathrm{BP}$ (DBP). The BP criterion for metabolic syndrome was defined as either a $\mathrm{SBP} \geq 130 \mathrm{~mm} \mathrm{Hg}, \mathrm{DBP} \geq 85 \mathrm{~mm} \mathrm{Hg}$, or current antihypertensive medication use. Plasma glucose, HDL cholesterol and serum triglycerides were measured by standard laboratory methods. Diabetes mellitus was defined as a plasma glucose $\geq 126$ $\mathrm{mg} / \mathrm{dl}$ after fasting for a minimum of $8 \mathrm{~h}$ and/or self-reported current use of antidiabetes medication. Finally, serum creatinine was measured by the modified kinetic Jaffe reaction and re-calibrated in order to calculate eGFR using the Modification of Diet in Renal Disease study equation.

Metabolic syndrome was defined using recent ATP-III guidelines [13] as the presence of at least three of the following five criteria: (1) history of hypertension, $\mathrm{SBP}>130 \mathrm{~mm} \mathrm{Hg}$, or DBP $>85$ $\mathrm{mm} \mathrm{Hg}$, (2) history of diabetes mellitus or elevated plasma glucose ( $\geq 100 \mathrm{mg} / \mathrm{dl}$ ), (3) waist circumference $>102 \mathrm{~cm}$ for men and $>88$ $\mathrm{cm}$ for women, (4) triglycerides $\geq 150 \mathrm{mg} / \mathrm{dl}$, and (5) $\mathrm{HDL}<40$ $\mathrm{mg} / \mathrm{dl}$ for men and $<50 \mathrm{mg} / \mathrm{dl}$ for women. A metabolic syndrome score (Metscore) was computed by adding the number of metabolic syndrome components present. 
Table 1. Demographics of those with and without metabolic syndrome (MS)

\begin{tabular}{|c|c|c|c|c|}
\hline Characteristic & MS present & MS absent & Totals & $\mathrm{p}$ value \\
\hline Number of participants & $2,568(65 \%)$ & $1,371(35 \%)$ & 3,939 & - \\
\hline Age, years & $58.9 \pm 10.5$ & $56.8 \pm 11.8$ & $58.2 \pm 11.0$ & $<0.0001$ \\
\hline Male gender & $1,391(54.4 \%)$ & $769(55.7 \%)$ & $2,160(54.8 \%)$ & 0.3752 \\
\hline Race & & & & $<0.0001$ \\
\hline Non-Hispanic White & $968(37.8 \%)$ & $670(48.5 \%)$ & $1,638(41.6 \%)$ & \\
\hline Non-Hispanic Black & $1,115(43.6 \%)$ & $536(38.8 \%)$ & $1,651(41.9 \%)$ & \\
\hline Hispanic & $381(14.9 \%)$ & $115(8.3 \%)$ & $496(12.6 \%)$ & \\
\hline Other & 94 (3.7\%) & $60(4.3 \%)$ & 154 (3.9\%) & \\
\hline Diabetes (present) & $1,666(65.1 \%)$ & $241(17.5 \%)$ & $1,907(48.4 \%)$ & $<0.0001$ \\
\hline $\mathrm{eGFR}, \mathrm{ml} / \mathrm{min} / 1.73 \mathrm{~m}^{2}$ & $41.3 \pm 13.0$ & $45.6 \pm 14.0$ & $42.8 \pm 13.5$ & $<0.0001$ \\
\hline Height, cm & $168.7 \pm 9.9$ & $169.0 \pm 9.4$ & $168.8 \pm 9.7$ & 0.4715 \\
\hline Weight, kg & $98.1 \pm 22.9$ & $79.3 \pm 19.0$ & $91.5 \pm 23.4$ & $<0.0001$ \\
\hline BMI & $34.4 \pm 7.6$ & $27.7 \pm 6.2$ & $32.1 \pm 7.8$ & $<0.0001$ \\
\hline Waist circumference, $\mathrm{cm}$ & $111.7 \pm 16.3$ & $94.8 \pm 14.3$ & $105.8 \pm 17.6$ & $<0.0001$ \\
\hline Number with waist circumference qualifying for MS & $2,140(84.3 \%)$ & $458(34.1 \%)$ & $2,598(66.9 \%)$ & $<0.0001$ \\
\hline $\mathrm{SBP}, \mathrm{mm} \mathrm{Hg}$ & $131.1 \pm 22.1$ & $123.6 \pm 21.6$ & $128.5 \pm 22.2$ & $<0.0001$ \\
\hline $\mathrm{DBP}, \mathrm{mm} \mathrm{Hg}$ & $71.4 \pm 12.9$ & $72.0 \pm 12.7$ & $71.6 \pm 12.8$ & 0.1110 \\
\hline Number with BP qualifying for MS & $2,441(95.1 \%)$ & $1,011(73.7 \%)$ & $3,452(87.6 \%)$ & $<0.0001$ \\
\hline Glucose, mg/dl & $125.1 \pm 54.6$ & $97.2 \pm 39.8$ & $115.4 \pm 51.7$ & $<0.0001$ \\
\hline Number with glucose qualifying for MS & $2,039(79.4 \%)$ & $309(22.5 \%)$ & $2,438(59.6 \%)$ & $<0.0001$ \\
\hline Serum creatinine, $\mathrm{mg} / \mathrm{dl}$ & $1.8 \pm 0.6$ & $1.7 \pm 0.6$ & $1.7 \pm 0.6$ & $<0.0001$ \\
\hline Triglyceride, $\mathrm{mg} / \mathrm{dl}$ & $185.5 \pm 131.2$ & $104.2 \pm 47.5$ & $157.3 \pm 116.3$ & $<0.0001$ \\
\hline Number with triglycerides qualifying for MS & $1,376(53 \%)$ & $126(9.2 \%)$ & $1,502(38.1 \%)$ & $<0.0001$ \\
\hline LDL, mg/dl & $100.2 \pm 36.2$ & $106.9 \pm 33.4$ & $102.5 \pm 35.4$ & $<0.0001$ \\
\hline $\mathrm{HDL}, \mathrm{mg} / \mathrm{dl}$ & $42.8 \pm 12.2$ & $56.4 \pm 17.0$ & $47.5 \pm 15.5$ & $<0.0001$ \\
\hline Number with HDL qualifying for MS & $1,728(67.3 \%)$ & $231(16.8 \%)$ & $1,959(49.7 \%)$ & $<0.0001$ \\
\hline Presence of any CVD & $979(38.1 \%)$ & $337(24.6 \%)$ & $1,316(33.4 \%)$ & $<0.0001$ \\
\hline
\end{tabular}

Data are expressed as mean $\pm \mathrm{SD}$ for continuous variables and as percentages for categorical variables.

This study was approved by the Institutional Review Boards for each of the participating centers and the Scientific and Data Coordinating Center (University of Pennsylvania) and written informed consent was obtained from all participants. This study also conformed to the Health Insurance Portability and Accountability Act (HIPAA) guidelines.

\section{Statistical Methods}

Baseline characteristics and measures were summarized as means [standard deviation (SD)] for continuous variables and as percentages for categorical variables overall and by metabolic syndrome status. The prevalence of metabolic syndrome and metabolic syndrome score categories (0-5) were calculated overall and by age, gender, race/ethnicity, and eGFR category $(<45,45-59$ and $\geq 60 \mathrm{ml} / \mathrm{min} / 1.73 \mathrm{~m}^{2}$ ). The prevalence of CVD at baseline was summarized across metabolic syndrome status and scores with differences assessed using the $\chi^{2}$ test. Next, prevalence ratios (PRs) adjusted for age, race/ethnicity, gender and eGFR were calculated using log binomial regression models. PRs are recommended, in lieu of odds ratios, for cross-sectional studies with common outcomes [14], and are calculated by determining the ratio of the \{probability of disease present and exposure present\} divided by the \{probability of disease present when exposure is absent\}. Anal- ysis of Metscore as a class variable meant treating the number of components of metabolic syndrome being present (1-5, except that in the case of diabetes, $2-5$, because everyone with diabetes has at least 1 component) and compared the PR for CVD at each level to the referent level of 0 components of metabolic syndrome (nondiabetics) and 1 component of metabolic syndrome (for the diabetics). The final multivariable-adjusted models were stratified by gender, race/ethnicity, eGFR and gender/race/ethnicity subgroups. We used the bayesian information criterion (BIC) to compare model fits. The BIC is calculated by regression software and equals the model deviance plus a penalty proportional to the number of parameters in the regression model and to the logarithm of the number of observations; model selection using BIC tends to produce parsimonious models. All analyses were conducted using SAS 9.2 (SAS Inc., Cary, N.C., USA).

\section{Results}

Characteristics of CRIC participants by metabolic syndrome status are provided in table 1. About twothirds of the CRIC participants (65\%) qualified for the 
Table 2. Metabolic syndrome components frequency in CRIC all participants, and by diabetic status

\begin{tabular}{|c|c|c|c|c|c|c|}
\hline \multirow{2}{*}{$\begin{array}{l}\text { Metabolic } \\
\text { syndrome } \\
\text { score }\end{array}$} & \multicolumn{2}{|c|}{$\begin{array}{l}\text { All } \\
\text { participants }\end{array}$} & \multicolumn{2}{|c|}{$\begin{array}{l}\text { Diabetes present } \\
(\mathrm{n}=1,907)\end{array}$} & \multicolumn{2}{|c|}{$\begin{array}{l}\text { Diabetes absent } \\
(\mathrm{n}=2,032)\end{array}$} \\
\hline & $\mathrm{n}$ & $\%$ & $\mathrm{n}$ & $\%$ & $\mathrm{n}$ & $\%$ \\
\hline 0 & 101 & 2.56 & & & 101 & 4.97 \\
\hline 1 & 405 & 10.3 & 24 & 1.26 & 381 & 18.8 \\
\hline 2 & 865 & 22.0 & 213 & 11.2 & 652 & 32.1 \\
\hline 3 & 1,110 & 28.2 & 601 & 31.5 & 509 & 25.0 \\
\hline 4 & 896 & 22.7 & 592 & 31.0 & 304 & 15.0 \\
\hline 5 & 562 & 14.3 & 477 & 25.0 & 85 & 4.18 \\
\hline
\end{tabular}

Table 3. Breakdown of metabolic syndrome component frequency

\begin{tabular}{|c|c|c|c|c|c|}
\hline \multirow{2}{*}{$\begin{array}{l}\text { Metabolic } \\
\text { syndrome } \\
\text { score }\end{array}$} & \multicolumn{5}{|c|}{ Metabolic syndrome component, \% } \\
\hline & $\begin{array}{l}\text { elevated } \\
\text { glucose }\end{array}$ & $\begin{array}{l}\text { increased waist } \\
\text { circumference }\end{array}$ & low HDL & $\begin{array}{l}\text { increased } \\
\mathrm{BP}\end{array}$ & $\begin{array}{l}\text { increased } \\
\text { triglycerides }\end{array}$ \\
\hline \multicolumn{6}{|c|}{ All participants } \\
\hline 0 & 0.0 & 0.0 & 0.0 & 0.0 & 0.0 \\
\hline 1 & 6.9 & 14.9 & 10.6 & 64.0 & 4.0 \\
\hline 2 & 32.5 & 47.1 & 21.7 & 86.9 & 12.7 \\
\hline 3 & 66.4 & 73.0 & 41.5 & 92.5 & 28.0 \\
\hline 4 & 82.6 & 88.2 & 78.7 & 95.1 & 56.1 \\
\hline 5 & 100 & 100 & 100 & 100 & 100 \\
\hline
\end{tabular}

\begin{tabular}{lrrrrr}
\hline Diabetics & & & & & \\
0 & - & - & - & - & - \\
1 & 100 & 0.0 & 0.0 & 0.0 & 0.0 \\
2 & 100 & 9.3 & 2.8 & 86.9 & 1.4 \\
3 & 100 & 72.3 & 22.3 & 93.0 & 14.3 \\
4 & 100 & 86.0 & 75.0 & 94.3 & 45.6 \\
5 & 100 & 100 & 100 & 100 & 100 \\
\hline
\end{tabular}

\begin{tabular}{lrrrrr}
\hline Non-diabetics & & & & & \\
0 & 0.0 & 0.0 & 0.0 & 0.0 & 0.0 \\
1 & 1.0 & 15.8 & 11.3 & 68.0 & 4.2 \\
2 & 10.4 & 59.2 & 27.9 & 87.0 & 16.4 \\
3 & 26.7 & 73.8 & 64.2 & 91.9 & 44.2 \\
4 & 48.7 & 92.4 & 85.9 & 96.7 & 76.6 \\
5 & 100 & 100 & 100 & 100 & 100 \\
\hline
\end{tabular}

diagnosis of metabolic syndrome. The race/ethnicity distribution of participants differed across those with and without metabolic syndrome, with fewer non-Hispanic Whites as well as more non-Hispanic Blacks and Hispanics meeting the criteria for the syndrome. Most characteristics itemized in table 1 were significantly different in

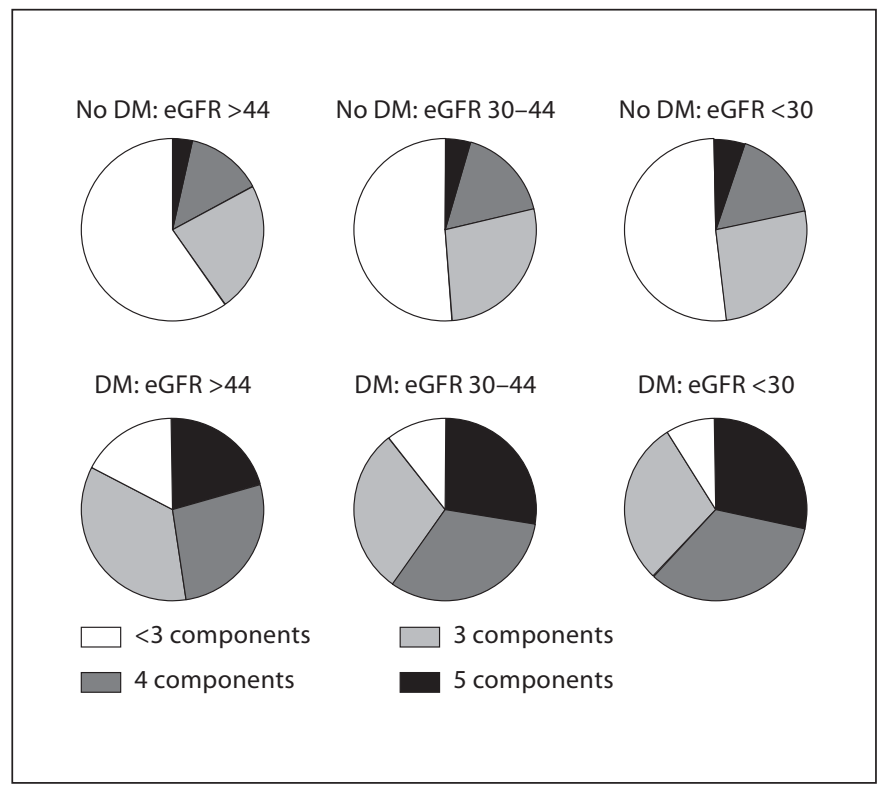

Fig. 1. Pie charts showing prevalence of metabolic syndrome in CKD in participants without (upper row) or with (lower row) diabetes. Each row is divided into three eGFR ranges, as labeled. Those with $<3$ metabolic syndrome components are the white slices beginning at the 12 o'clock position going counterclockwise. The next slices, continuing counterclockwise, represent 3, 4 or all 5 metabolic syndrome components.

those with compared with those without metabolic syndrome, except for DBP and height.

Table 2 shows the distribution of metabolic syndrome components among CRIC participants. Fewer than 3\% of the CRIC participants had no metabolic syndrome component and nearly $15 \%$ of the CRIC participants had all 5 components. When broken down by diabetes status, $87.5 \%$ of our participants with diabetes and $44.3 \%$ of our non-diabetic participants had metabolic syndrome. Figure 1 presents the prevalence of metabolic syndrome by diabetes and kidney function status, showing the substantial prevalence of 3 or more components in participants with diabetes and CKD.

Table 3 shows, by the total number of metabolic syndrome components present, the distribution of the metabolic syndrome components. The most common component was the presence of a BP $>130 / 85 \mathrm{~mm} \mathrm{Hg}$ or use of antihypertensive medications. The least common component was a serum triglyceride concentration $>150$ $\mathrm{mg} / \mathrm{dl}$.

Table 4 compares the PR of any CVD for a diagnosis of metabolic syndrome and for each of the individual com- 
Table 4. Adjusted ${ }^{1}$ models of PRs of metabolic syndrome and presence of any CVD

\begin{tabular}{|c|c|c|c|c|c|c|c|}
\hline $\begin{array}{l}\text { Model } \\
\text { No. }\end{array}$ & Model characteristic & All participants & $\mathrm{p}$ value & Diabetics (only) & $\mathrm{p}$ value & $\begin{array}{l}\text { Non-diabetics } \\
\text { (only) }\end{array}$ & $\mathrm{p}$ value \\
\hline 1 & Metabolic syndrome & $1.16(1.04-1.30)$ & 0.0087 & $1.08(0.91-1.28)$ & 0.3544 & $1.22(1.06-1.42)$ & 0.0063 \\
\hline \multirow[t]{5}{*}{2} & Metscore 1 (class) & $1.45(0.76-2.77)$ & $<0.0001$ & referent & & $1.24(0.65-2.38)$ & 0.0007 \\
\hline & Metscore 2 & $1.93(1.03-3.59)$ & - & $0.82(0.47-1.42)$ & 0.0138 & $1.69(0.90-3.16)$ & - \\
\hline & Metscore 3 & $1.91(1.03-3.56)$ & - & $0.80(0.47-1.35)$ & - & $1.77(0.94-3.32)$ & - \\
\hline & Metscore 4 & $2.25(1.21-4.19)$ & - & $0.98(0.58-1.66)$ & - & $1.83(0.97-3.46)$ & - \\
\hline & Metscore 5 & $2.26(1.21-4.22)$ & - & $0.94(0.55-1.59)$ & - & $2.52(1.30-4.88)$ & - \\
\hline 3 & Metscore (continuous) & $1.09(1.05-1.14)$ & $<0.0001$ & $1.07(1.01-1.12)$ & 0.0152 & $1.14(1.07-1.21)$ & $<0.001$ \\
\hline \multirow[t]{5}{*}{4} & Glucose & $1.18(1.01-1.39)$ & $<0.0471$ & - & - & $1.10(0.94-1.29)$ & 0.2606 \\
\hline & HDL cholesterol & $1.20(1.10-1.31)$ & $<0.0001$ & $1.25(1.12-1.40)$ & $<0.0001$ & $1.12(0.96-1.30)$ & 0.1487 \\
\hline & Hypertension & $1.10(0.91-1.32)$ & 0.3059 & $0.80(0.67-0.95)$ & 0.0238 & $1.69(1.22-2.34)$ & 0.0005 \\
\hline & Triglycerides & $0.98(0.90-1.07)$ & 0.7238 & $0.96(0.86-1.07)$ & 0.4601 & $1.04(0.88-1.22)$ & 0.6474 \\
\hline & Waist circumference & $1.08(0.97-1.19)$ & 0.1559 & $1.04(0.91-1.18)$ & 0.5677 & $1.19(1.01-1.39)$ & 0.0338 \\
\hline
\end{tabular}

${ }^{1}$ Models adjusted for age, gender, ethnicity, eGFR and clinical site; data are 'mean (95\% confidence intervals)'.

Table 5. BIC statistic for the four models of the relationship of metabolic syndrome and its components to prevalent CVD

\begin{tabular}{|c|c|c|c|}
\hline \multirow[t]{2}{*}{ Model No. } & \multicolumn{3}{|l|}{ BIC statistic } \\
\hline & all participants & diabetics (only) & non-diabetics (only) \\
\hline Covariates $^{1}$ only & $4,576.4$ & $2,534.1$ & $2,133.9$ \\
\hline 1 Metabolic syndrome (binary) & $4,577.8$ & $2,540.8$ & $2,134.1$ \\
\hline 2 Metabolic syndrome (class) & $4,589.0$ & $2,551.7$ & $2,150.7$ \\
\hline 3 Metabolic syndrome as a score (continuous) & $4,564.2$ & $2,535.7$ & $2,124.9$ \\
\hline $\begin{array}{l}4 \text { Metabolic syndrome components (binary } \\
\text { subcomponents of metabolic syndrome definition) }\end{array}$ & $4,588.9$ & $2,540.0$ & $2,146.8$ \\
\hline
\end{tabular}

${ }^{1}$ Age, race, sex, eGFR, and clinical site.

ponents of metabolic syndrome separately. In addition, these relationships were stratified by the presence or absence of diabetes. Four models of metabolic syndrome are presented. In model 1, metabolic syndrome is treated as a dichotomous variable (yes or no). Interestingly, the PR for CVD of non-diabetics with metabolic syndrome was actually higher than that of diabetics with metabolic syndrome. In model 2, metabolic syndrome is treated as a class variable. The statistical comparisons are the individual Metscore values to a value of 0 . The indicated $p$ values are for the overall model, showing some predictive potential overall, but little or no significant prediction in the diabetic or non-diabetic subgroups. In model 3, metabolic syndrome score was treated as a single interval-scaled variable. This model showed the best prediction (table 5). In model 3, we observed that each increment in the number of metabolic syndrome factors present increased the PR for CVD by $9 \%$. In model 4 , we examined metabolic syndrome by the individual components of the definition of metabolic syndrome in a binary fashion. This model performed well in the non-diabetics but not as well in the diabetics. Of note, in the diabetics, the hypertension criterion (BP $>130 / 85 \mathrm{~mm} \mathrm{Hg}$ or on antihypertensive medications) had a PR that appeared protective against CVD. 
In table 5, we present the results of four models of metabolic syndrome testing the model fit characteristics using the BIC, where smaller values indicate a better fit. BIC substantially penalizes more complex models, as is appropriate in coming up with simple models for clinical use. Thus, some variables with statistically significant associations with outcome were not included. The best fit appeared to be model 3 which treated metabolic syndrome as a single interval-scaled variable taking on values of 1 through 5 .

\section{Discussion}

Our data present four important findings derived from a large diverse population of participants with CKD. The first finding is the high prevalence of metabolic syndrome in CKD. Nearly 2 out of 3 participants (65\%) in the CRIC Study satisfy the ATP-III diagnostic criteria for metabolic syndrome, with a noteworthy proportion (44.3\%) of participants without diabetes fulfilling metabolic syndrome criteria. Such a high proportion of metabolic syndrome in diabetics ( $87 \%$ in the current study) was also noted by Alexander et al. [15] in the NHANESIII population. Reported prevalence of metabolic syndrome in the USA has been increasing, in step with the growing problem of obesity. In recent studies, the metabolic syndrome prevalence in adults in the USA increases with age and ranges from 22 to $35 \%$ [10, 16, 17]. Even in the absence of diabetes, the prevalence of metabolic syndrome in our CKD population is nearly twice as high as in other recently reported cohorts. The recently reported association between metabolic syndrome and decline in kidney function with more components of the syndrome showing a greater decline underscores the clinical importance of this finding. In the Atherosclerosis Risk in Communities (ARIC) Study, those with all 5 metabolic syndrome components had a nearly 2.5 -fold higher odds of developing CKD compared with no components during a 9-year follow-up [18]. The mechanism by which metabolic syndrome participates in accelerating the loss of kidney function may be through hyperfiltration, supported by studies such as that of Chagnac et al. [19], which demonstrated a greater degree of hyperfiltration in subjects with severe obesity compared with similar aged controls. In addition, elevated insulin concentrations, a consequence of the insulin resistance thought to underlie the metabolic syndrome, is another potential mediator by increased renal blood flow through its vasodilatory effects on the kidney circulation [20].
Secondly, there is substantial variability in the prevalence of the individual components of the metabolic syndrome with elevated BP present more than twice as often as elevated triglyceride levels. Non-CKD populations like NHANES [15] show a higher prevalence of elevated triglyceride concentration, but similar prevalence in waist circumference, HDL and BP criterion.

Third, metabolic syndrome was associated with prevalent CVD at enrollment into CRIC overall, but it improves model fit as measured by BIC only among those without diabetes when stratified for this. This latter point is particularly noteworthy and suggests that perhaps the designation of metabolic syndrome is less important than understanding the individual risk factors present among CKD patients with diabetes.

Lastly our data show that simply counting up the number of metabolic syndrome components (i.e. 1-5 components being present in any individual) showed the best model characteristics as evaluated using the BIC compared with the presence of metabolic syndrome or the individual components of it. This suggests that dichotomization into a binary diagnosis of metabolic syndrome unnecessarily reduces information for predicting CVD. While the use of the score or its individual components may somewhat improve prediction, this comes at a price of increased model complexity and difficulty of interpretation and use which may not be warranted in many clinical settings.

The metabolic syndrome was described to characterize cardiovascular risk capitalizing on the well-known finding that $\mathrm{CV}$ risk factors tend to 'cluster' in individuals with upper body obesity [21]. In recent years, the association of metabolic syndrome with CVD has been called into question by arguments that cast doubt on its value in CVD risk recognition since the components alone appear to be equally predictive [22]. As depicted in table 4, the only individual component with a stronger association with prevalent CVD among participants without diabetes as assessed by the adjusted PR was hypertension, which was present in $87.6 \%$ of our participants. The presence of hypertension doubles the likelihood of having metabolic syndrome when compared to the general nonhypertensive population and metabolic syndrome in hypertensives generally heightens the risk of CVD [23]. Our data showed that hypertension appeared to be 'protective' from CVD in the diabetics with metabolic syndrome. Although this at first seems counterintuitive, it may be that those with diabetes and increased BP were treated earlier and more aggressively compared to those diabetics without a diagnosis of hypertension with drugs blocking the 
renin-angiotensin system. Sixty-seven percent of the diabetics without metabolic syndrome reported taking an ACE inhibitor or an angiotensin receptor blocker, while $80 \%$ of the diabetics with metabolic syndrome were treated with these drugs in CRIC. Each of these drug classes has an agent with an indication for high cardiovascular risk ('Expanded indication for Telmisartan FDA' http:// www.theheart.org/article/1014115.do and 'Ramipril FDA approval for high CV risk' http://www.pslgroup.com/ $\mathrm{dg} / 1 \mathrm{e} 36 \mathrm{a} 6 . \mathrm{htm}$ both accessed January 11, 2011). In addition, the dialysis experience also somewhat paradoxically suggests that lower BPs are associated with a greater risk of cardiovascular death [24].

Our findings regarding metabolic syndrome in CKD add to the literature, given the large size of our CKD population, about half of whom were diabetic and about half of whom were African-American. We acknowledge several limitations including the cross-sectional nature of the analyses and the self-report of prevalent CVD.

In summary, we observed a high prevalence of metabolic syndrome in a population of subjects all of whom have CKD compared to that reported in the general population without diabetes. Hypertension was the component most often present in our CKD population fulfilling the criteria for metabolic syndrome. The presence of metabolic syndrome was associated with a significant PR for CVD at enrollment into the CRIC study, but only among those without diabetes. The longitudinal nature of the CRIC study provides an ideal setting to determine prospectively the predictive value of metabolic syndrome, compared to individual components, both on kidney function decline and on worsening of existing CVD and incident cardiovascular outcomes in an already high-risk population, those with established CKD.

\section{Acknowledgments}

This work was supported by NIH grants U01-DK-060984 and UL1-RR-024134. R.R.T. was funded by a grant from NIH/ NIDDK.

\section{References}

1 Go AS, Chertow GM, Fan D, McCulloch CE, Hsu CY: Chronic kidney disease and the risks of death, cardiovascular events, and hospitalization. N Engl J Med 2004;351: 1296-1305.

-2 Shlipak MG, Fried LF, Cushman M, Manolio TA, Peterson D, Stehman-Breen C, Bleyer A, Newman A, Siscovick D, Psaty B: Cardiovascular mortality risk in chronic kidney disease: comparison of traditional and novel risk factors. JAMA 2005;293:1737-1745.

>3 Muntner P, He J, Hamm L, Loria C, Whelton PK: Renal insufficiency and subsequent death resulting from cardiovascular disease in the United States. J Am Soc Nephrol 2002; 13:745-753.

4 Shlipak MG, Katz R, Sarnak MJ, Fried LF, Newman AB, Stehman-Breen C, Seliger SL, Kestenbaum B, Psaty B, Tracy RP, Siscovick DS: Cystatin $C$ and prognosis for cardiovascular and kidney outcomes in elderly persons without chronic kidney disease. Ann Intern Med 2006;145:237-246.

5 Isomaa B, Almgren P, Tuomi T, Forsen B, Lahti K, Nissen M, Taskinen MR, Groop L: Cardiovascular morbidity and mortality associated with the metabolic syndrome. Diabetes Care 2001;24:683-689.
-6 Lakka HM, Laaksonen DE, Lakka TA, Niskanen LK, Kumpusalo E, Tuomilehto J, Salonen JT: The metabolic syndrome and total and cardiovascular disease mortality in middle-aged men. JAMA 2002;288:2709-2716.

-7 Ford ES: Risks for all-cause mortality, cardiovascular disease, and diabetes associated with the metabolic syndrome: a summary of the evidence. Diabetes Care 2005;28:1769-1778.

$\checkmark 8$ Galassi A, Reynolds K, He J: Metabolic syndrome and risk of cardiovascular disease: a meta-analysis. Am J Med 2006;119:812-819.

-9 Gami AS, Witt BJ, Howard DE, Erwin PJ, Gami LA, Somers VK, Montori VM: Metabolic syndrome and risk of incident cardiovascular events and death: a systematic review and meta-analysis of longitudinal studies. J Am Coll Cardiol 2007;49:403-414.

10 Chen J, Muntner P, Hamm LL, Jones DW, Batuman V, Fonseca V, Whelton PK, He J: The metabolic syndrome and chronic kidney disease in US adults. Ann Intern Med 2004;140: $167-174$.

11 Lea J, Cheek D, Thornley-Brown D, Appel L, Agodoa L, Contreras G, Gassman J, Lash J, Miller ER III, Randall O, Wang X, McClellan $\mathrm{W}$ : Metabolic syndrome, proteinuria, and the risk of progressive CKD in hypertensive African-Americans. Am J Kidney Dis 2008; 51:732-740.
$>12$ Feldman HI, Appel LJ, Chertow GM, Cifelli D, Cizman B, Daugirdas J, Fink JC, FranklinBecker ED, Go AS, Hamm LL, He J, Hostetter T, Hsu CY, Jamerson K, Joffe M, Kusek JW, Landis JR, Lash JP, Miller ER, Mohler ER III, Muntner P, Ojo AO, Rahman M, Townsend RR, Wright JT: The Chronic Renal Insufficiency Cohort (CRIC) Study: design and methods. J Am Soc Nephrol 2003; 14:S148-S153.

13 Alberti KG, Eckel RH, Grundy SM, Zimmet PZ, Cleeman JI, Donato KA, Fruchart JC, James WP, Loria CM, Smith SC Jr: Harmonizing the metabolic syndrome: a joint interim statement of the International Diabetes Federation Task Force on Epidemiology and Prevention; National Heart, Lung, and Blood Institute; American Heart Association; World Heart Federation; International Atherosclerosis Society; and International Association for the Study of Obesity. Circulation 2009;120:1640-1645.

- 14 Behrens T, Taeger D, Wellmann J, Keil U: Different methods to calculate effect estimates in cross-sectional studies. A comparison between prevalence odds ratio and prevalence ratio. Methods Inf Med 2004;43:505509. 
-15 Alexander CM, Landsman PB, Teutsch SM, Haffner SM: NCEP-defined metabolic syndrome, diabetes, and prevalence of coronary heart disease among NHANES-III participants age 50 years and older. Diabetes 2003; 52:1210-1214.

${ }_{16}$ Bertoni AG, Wong ND, Shea S, Ma S, Liu K, Preethi S, Jacobs DR Jr, Wu C, Saad MF, Szklo M: Insulin resistance, metabolic syndrome, and subclinical atherosclerosis: the Multi-Ethnic Study of Atherosclerosis (MESA). Diabetes Care 2007;30:2951-2956.

$\checkmark 17$ Ford ES, Giles WH, Dietz WH: Prevalence of the metabolic syndrome among US adults: findings from the third National Health and Nutrition Examination Survey. JAMA 2002; 287:356-359.
Kurella M, Lo JC, Chertow GM: Metabolic syndrome and the risk for chronic kidney disease among nondiabetic adults. J Am Soc Nephrol 2005; 16:2134-2140.

19 Chagnac A, Weinstein T, Korzets A, Ramadan E, Hirsch J, Gafter U: Glomerular hemodynamics in severe obesity. Am J Physiol Renal Physiol 2000;278:F817-F822.

20 Perlstein TS, Gerhard-Herman M, Hollenberg NK, Williams GH, Thomas A: Insulin induces renal vasodilation, increases plasma renin activity, and sensitizes the renal vasculature to angiotensin receptor blockade in healthy subjects. J Am Soc Nephrol 2007;18: 944-951.

21 Kaplan NM: The deadly quartet. Upperbody obesity, glucose intolerance, hypertriglyceridemia, and hypertension. Arch Intern Med 1989;149:1514-1520.
22 Kahn R, Buse J, Ferrannini E, Stern M: The metabolic syndrome: time for a critical appraisal: joint statement from the American Diabetes Association and the European Association for the Study of Diabetes. Diabetes Care 2005;28:2289-2304.

23 Natali A, Pucci G, Boldrini B, Schillaci G: Metabolic syndrome: at the crossroads of cardiorenal risk. J Nephrol 2009;22:29-38.

24 Covic A, Gusbeth-Tatomir P, Goldsmith DJ: The challenge of cardiovascular risk factors in end-stage renal disease. J Nephrol 2003; 16:476-486. 


\section{Erratum}

In reference to the manuscript entitled 'Metabolic Syndrome, Components, and Cardiovascular Disease Prevalence in Chronic Kidney Disease: Findings from the Chronic Renal Insufficiency Cohort (CRIC) Study' by Townsend et al. [Am J Nephrol 2011;33:477484], the following grant acknowledgments were inadvertently omitted by the authors: (a) University of Pennsylvania Scientific \& Data Coordinating Center U01DK060990; (b) The Johns Hopkins University UL1 RR-025005; (c) University of Maryland GCRC M01 RR-16500; (d) Case Western Reserve University Clinical and Translational Science Collaborative (University Hospitals of Cleveland, Cleveland Clinic Foundation, and MetroHealth) UL1 RR-024989; (e) University of Michigan M01 RR-000042 and UL1 RR024986; (f) University of Illinois at Chicago CTSA UL1RR029879; (g) Tulane/LSU/Charity Hospital General Clinical Research Center RR-05096, and (h) Kaiser NIH/NCRR UCSF-CTSI UL1 RR-024131. 